Authors Version

Comparative Study of EB-PVD Gadolinium-zirconate and Yttria-rich zirconia coatings performance against Fe-containing CMAS infiltration.

by

Juan J. Gomez Chavez ${ }^{\mathrm{a}, \mathrm{b}}$, Ravisankar Naraparaju ${ }^{\mathrm{b}}$, Christoph Mikulla ${ }^{\mathrm{b}}$, Peter Mechnich ${ }^{\mathrm{b}}$, Klemens Kelm ${ }^{\mathrm{b}}$, C.V. Ramana ${ }^{\mathrm{a}}$ and Uwe Schulz ${ }^{\mathrm{b}}$

${ }^{\text {a }}$ Department of Mechanical Engineering, University of Texas at El Paso, El Paso, TX, 79968, USA

${ }^{\mathrm{b}}$ German Aerospace Center (DLR), Institute of Materials Research, Cologne, 51170, Germany Corrosion Science 190 (2021) 109660

https://doi.org/10.1016/j.corsci.2021.109660 


\title{
Comparative Study of EB-PVD Gadolinium-zirconate and Yttria-rich zirconia coatings performance against Fe-containing CMAS infiltration.
}

\begin{abstract}
This current study compares the CMAS resistance behavior of EB-PVD gadolinium zirconate (GZO) and yttria rich zirconia $\left(65 \mathrm{YZ}, 65 \mathrm{wt} \% \mathrm{Y}_{2} \mathrm{O}_{3}\right.$ rest zirconia) coatings. The infiltration kinetics, as well as the stability and protective nature of different reaction products, was studied by performing long term infiltration tests (up to $50 \mathrm{~h}$ ) at $1250{ }^{\circ} \mathrm{C}$. The results reveal that for the specific microstructures used in this study, $65 \mathrm{YZ}$ has a higher infiltration resistance and forms a thinner reaction layer compared to GZO. The analysis indicates that the better performance of $65 \mathrm{YZ}$ is associated with a synergetic reaction mechanism, which includes the formation of Ca-rich apatite and a uniform layer of a garnet phase. The formation of apatite requires more Rare Earth (RE) in the case of GZO than its $65 \mathrm{YZ}$ counterpart, meaning that more Gd would be dissolved before forming apatite crystals, which leads to higher consumption of the GZO layer compared to that of $65 \mathrm{YZ}$. The implications of these mechanisms are discussed in detail concerning the tendency of garnet formation, equilibration of the apatite phase with $\mathrm{Ca}$ and $\mathrm{RE}$ content, and the effects of the reduction in viscosity due to the RE dissolution into the glass. However, microstructural differences in the coatings used in this study might also affect the diverging infiltration resistance and reaction kinetics and need to be considered.
\end{abstract}

\section{$\underline{\text { 1. Introduction }}$}

Modern gas turbines are protected with ceramic thermal barrier coatings (TBC) to provide thermal insulation to the underlying metallic components thus, increasing engine efficiency [16]. The most widely used TBC material is the state-of-the-art yttria stabilized zirconia (YSZ). The standard production method for TBCs is via electron-beam physical vapor deposition (EBPVD) or atmospheric plasma spray (APS). These methods produce different configurations of porous microstructures that are required to provide strain tolerance and reduce further the thermal conductivity [7]. The current demand in the industry for more efficient engines that can achieve higher operating temperatures (up to $1500{ }^{\circ} \mathrm{C}$ ) has brought into attention the novel corrosion issue, precisely due to the ingestion of siliceous based airborne debris or CMAS [6, $8,9]$. This type of debris is mainly made of $\mathrm{CaO}-\mathrm{MgO}-\mathrm{Al}_{2} \mathrm{O}_{3}-\mathrm{SiO}_{2}$, and their sources include dust, sand, volcanic ash, fly ash, environmental pollution, etc. The typical CMAS attack in gas turbines is due to the deposition of molten CMAS glassy particles on the hot gas path components, which subsequently infiltrate the porous TBC network. As the molten glass penetrates the porous TBC, it changes its mechanical properties, which leads to premature coating spallation [10]. The most studied CMAS mitigation strategies are based on the deposition of a sacrificial oxide coating, which uses a reactive material, commonly rare earth (RE) based oxide. This RE material reacts with the molten CMAS glass and induces its crystallization into stable silicate-based reaction products such as apatite [11-19]. Other approaches use different TBC doping materials to shift the CMAS crystallization into the stable 
anorthite field $[11,20]$ and also focus on tailor the TBC microstructure to reduce the CMAS infiltration $[21,22]$.

A pre-requisitive for any TBC material to be CMAS resistant is its ability to react quickly upon interaction with the molten CMAS glass-forming stable reaction phases. Then, the reaction phases must nucleate in a beneficial shape, which promotes the seal of the open porosities in the TBC, maintaining a shallow infiltration. Up to now, it is still unclear which RE based coating gives the best performance against CMAS infiltration. Additionally, since the range of chemical composition of CMAS bearing compounds is vast [8], it is still not clear how a RE oxide-based TBC will perform against different variations of CMAS compositions. The current work compares the CMAS infiltration behavior of EB-PVD $65 \mathrm{YZ}$ and GZO coatings for infiltration times of $50 \mathrm{~h}$ at $1250^{\circ} \mathrm{C}$. Their infiltration performance is evaluated for a broader range of CMAS compositions covering synthetic compounds and natural volcanic ash. The performance is compared based on the formed reaction phases (focusing on apatite and garnet) and viscosity variations.

\section{Experimental Details}

\subsection{TBC deposition}

Yttria-zirconia coatings with a nominal composition of 65 wt. $\% \mathrm{Y}_{2} \mathrm{O}_{3}$ and rest $\mathrm{ZrO}_{2}(65 \mathrm{YZ})$ or translated to $67 \mathrm{YO}_{1.5} \mathrm{~mol} \%$ rest $\mathrm{ZrO}_{2}$ were prepared using EB-PVD on top of $1 \mathrm{~mm}$ thick $\mathrm{Al}_{2} \mathrm{O}_{3}$ substrates. The evaporation was performed using a single ingot source with a nominal yttria-zirconia composition as specified above. The substrate material was selected to allow for high-temperature infiltration testing $\left(1250^{\circ} \mathrm{C}\right)$, which could not be done using Ni-based superalloy substrates for long time periods (up to $50 \mathrm{~h}$ ). Additionally, Gadolinium zirconate (GZO) samples were also prepared using EB-PVD on top of alumina substrates. The deposition parameters for both sample types are specified in Table 1.

\subsection{CMAS Materials}

A variety of CMAS compositions were tested; however, the majority of the investigations focused on the reactions with one CMAS compound denominated CMAS 1 with a nominal composition of $\mathrm{C}_{22} \mathrm{M}_{11} \mathrm{~A}_{20} \mathrm{~S}_{38} \mathrm{~F}_{8} \mathrm{~T}_{1}$ in mole \%. Each letter refers to every single oxide in a single cation basis for better comparability $\left(\mathrm{CaO}, \mathrm{MgO}, \mathrm{AlO}_{1.5}, \mathrm{SiO}_{2}, \mathrm{FeO}, \mathrm{TiO}_{2}\right)$. This single cation nomenclature is used throughout this paper to simplify measurements. Therefore, yttria and zirconia are referred to as $\mathrm{YO}_{1.5}$ and $\mathrm{ZrO}_{2}$, respectively. This CMAS source has been used extensively in a large variety of studies [17, 21-24]. Its chemical composition was obtained from analyzing real engine hardware, which was operated in middle-eastern countries [24]. Its synthesis method is specified elsewhere $[23,24]$.

Additionally, complementary infiltration tests were performed using three more CMAS sources $\left(\mathrm{C}_{28} \mathrm{M}_{10} \mathrm{~A}_{18} \mathrm{~S}_{35} \mathrm{~F}_{7} \mathrm{~T}_{1}\right.$ referred to as CMAS 2, $\mathrm{C}_{33} \mathrm{M}_{9} \mathrm{~A}_{13} \mathrm{~S}_{45}$ referred to as UCSB CMAS and natural volcanic ash obtained from the Eyjafjallajökull volcano located in Iceland $\mathrm{C}_{11} \mathrm{M}_{6} \mathrm{~A}_{13} \mathrm{~S}_{45} \mathrm{~F}_{16} \mathrm{~T}_{4} \mathrm{~L}_{5}$ ( $\mathrm{L}$ refers to the sum of $\mathrm{NaO}_{0.5}$ and $\mathrm{KO}_{0.5}$ ) . The purpose of the complementary infiltration experiments was to compare the infiltration resistance of $65 \mathrm{YZ}$ or GZO with a broader spectrum of CMAS sources. Additionally, the apatite phase composition 
after $50 \mathrm{~h}$ formed in the reaction layer (defined as the interface layer of reaction products form in between the unreacted glass and the unreacted coating) for every sample was studied in detail by tracking its compositional changes with respect to the different $\mathrm{CaO}$ contents in the CMAS source. The details are provided in the discussion section.

\subsection{Infiltration experiments and characterization}

The infiltration experiments were carried out by depositing the various CMAS powders on top of the TBC coated samples in the amounts of $20 \mathrm{mg} / \mathrm{cm}^{2}$. The heat treatment was done isothermally at $1250^{\circ} \mathrm{C}$ for time ranges from 5 to $50 \mathrm{~h}$, followed by air quenching to room temperature at a cooling rate of $18 \mathrm{~K} / \mathrm{s}$. After infiltration tests, the samples were embedded in a low viscosity epoxy (Gatan G2) and cut in cross-sections using a high-speed diamond saw. The cross-sectioned samples were mounted in a carbon-based conductive resin and polished using standard metallographic techniques to a $0.05 \mu \mathrm{m}$ surface finish. Scanning electron microscopy (SEM) was performed on the samples using a Ultra 55 (Carl Zeiss NTS, Oberkochen, Germany) SEM microscope. The microscope was equipped with an energy dispersive X-Ray spectroscopy (EDS) system (Inca, Oxford Instruments, Abingdon, UK), which was used to determine the composition of the crystalline phases. Focused ion beam (FIB) assisted analytical transmission electron microscopy (TEM) was done using Strata 205 and Helios 600i FIB machines (FEI Inc., Eindhoven, Netherlands) and a Tecnai F30 TEM-STEM utilizing a field-emission gun (Philips BV, Eindhoven, Netherlands).

\section{Results}

\subsection{Characteristics of as-deposited EB-PVD coatings}

SEM cross-section images of both $65 \mathrm{YZ}$ and GZO are shown in Figure $\mathbf{1}$ in the as-coated state. The coatings exhibited mostly a parallel columnar microstructure, which is a characteristic property of EB-PVD TBCs similar to that of standard 7YSZ EB-PVD coatings. The 65YZ coating produced by single-source evaporation developed a much more homogeneous columnar structure than a TBC of similar composition obtained by two-source evaporation in previous studies [25]. The top surface view of the $65 \mathrm{YZ}$ samples exhibits a more ordered pyramidal arrangement of columns distributed asymmetrically compared to its GZO counterpart, as seen in Figure 1a and $\mathbf{b}$. Additionally, the columnar arrangement of the coatings in the cross-section view (Figure 1c and d) show more perpendicular columnar growth with respect to the substrate for the $65 \mathrm{YZ}$ case.

The GZO coatings also exhibit a columnar structure, but its microstructure differs significantly from the $65 \mathrm{YZ}$ coating in terms of thickness, curvature, and columnar morphology. The uppermost $50 \mu \mathrm{m}$ of the $65 \mathrm{YZ}$ coating exhibit an average column diameter of $6.1 \pm 1.8 \mu \mathrm{m}$ and inter-columnar gap width of $0.8 \pm 0.4 \mu \mathrm{m}$, whereas GZO coating experiences column diameters of $(15.6 \pm 1.0 \mu \mathrm{m})$ and inter-columnar gap widths of $1.7 \pm 1.3 \mu \mathrm{m}$. The coating thickness was measured in the range of 92 to $100 \mu \mathrm{m}$ for $65 \mathrm{YZ}$ and 330 to $340 \mu \mathrm{m}$ for GZO. While the $65 \mathrm{YZ}$ columns are straight, the GZO columns are bent for the initial $170 \mu \mathrm{m}$ from the substrate, followed by a straightening of the columns. The reason for this discontinuous change in 
microstructure is still under investigation. The upper $160 \mu \mathrm{m}$ of GZO coating shows a different microstructure with significantly larger columns and wider intercolumnar gaps. The current GZO morphology was selected from a larger pool of microstructures that are part of an ongoing study to understand the influence of the EB-PVD microstructure of GZO on its CMAS infiltration resistance. The overall porosity of the upper part of the coating was measured using imaging software (Image $J$ ) at the cross-section view giving porosity values of $20.5 \pm 2.6$ and $19.2 \pm 0.5$ for $65 \mathrm{YZ}$ and GZO, respectively. The summary of deposition parameters, thickness, and porosity for the produced coatings is given in Table $\mathbf{1}$.

Since yttrium and zirconium peaks overlap in the EDS spectra in SEM, the chemical composition of the 65YZ columns was justified using EDS analysis on a TEM lamella. The composition was consistent at 65 wt. \% $\mathrm{Y}_{2} \mathrm{O}_{3}-\mathrm{ZrO}_{2}$ balanced (about 67 to $70 \mathrm{YO}_{1.5} \mathrm{~mol}$. \%) with the overall composition of the ingot evaporation source. The TEM diffraction patterns of the as coated 65YZ samples (shown in Figure 2) confirmed a cubic yttria phase. According to TEM-EDS mappings, zirconia is evenly distributed in solid solution. The samples exhibited a columnar arrangement with the column axis parallel to the crystallographic [100] axis of the cubic $65 \mathrm{YZ}$ structure, possibly due to the texture arising from the deposition process as exhibited for EB-PVD 7YSZ TBCs [26] as well as MOCVD yttria rich-zirconia and pure yttria coatings produced by Eils et al. [13]. The GZO samples exhibited a cubic phase for $\mathrm{Gd}_{2} \mathrm{Zr}_{2} \mathrm{O}_{7}$ confirmed by XRD measurements.

\subsection{CMAS 1 Degradation}

The SEM cross-section images for the CMAS $1\left(\mathrm{C}_{22} \mathrm{M}_{11} \mathrm{~A}_{20} \mathrm{~S}_{38} \mathrm{~F}_{8} \mathrm{~T}_{1}\right) 50 \mathrm{~h}$ infiltrated $65 \mathrm{YZ}$ and GZO at $1250^{\circ} \mathrm{C}$ are shown in Figure 3. The summary of compositions measured with EDS for the reaction products of both $65 \mathrm{YZ}$ and GZO is given in Table 2. The $65 \mathrm{YZ}$ sample had an overall CMAS infiltration depth of $58 \mu \mathrm{m} \pm 5$, whereas the GZO counterpart with its wider intercolumnar gaps exhibited an overall infiltration depth of $150 \mu \mathrm{m} \pm 20$. The overall infiltration zones are delimited with the dashed blue curved lines in Figure 3c and Figure 3d for $65 \mathrm{YZ}$ and GZO, respectively. The infiltration zone appears to be discontinuous due to the variation of the inter-columnar gap width in both coatings.

The reduced overall infiltration depth compared to previous studies using $65 \mathrm{YZ}$ samples produced by dual-source jumping beam evaporation ( $65 \mu \mathrm{m}$ infiltration after $20 \mathrm{~h}$ at $1250{ }^{\circ} \mathrm{C}$ [17]) is attributed to single-source evaporation used in this work which created a different morphology of the TBC. Additionally, the 65YZ sample left a $\sim 120 \mu \mathrm{m}$ thick (not shown in SEM images) unreacted glass deposit. In contrast, very minimal unreacted glass deposits were found only sporadically on top of the reacted GZO layer. The reaction zone is defined as the area located between the unreacted glass reservoir and the unreacted TBC in this study. It is characterized by a uniform layer of reacted products from the glass/TBC interaction. Thus, the reaction zone appears to be distinct for both samples, i.e., for the $65 \mathrm{YZ}$, a uniform continuous $16 \mu \mathrm{m}$ thick garnet layer $(\mathrm{G})$ is clearly distinguished in Figure 3. A noticeable change in the reaction zone was observed for GZO comprising irregularly distributed garnet crystals within the size range of $20-150 \mu \mathrm{m}$ (width) covering approximately $20-25 \%$ of the surface on top of a continuous secondary layer made of a combination of apatite (A) and fluorite (F) equally dispersed crystals. The reaction layer is delimited within the square bracket (RL) in Figure 3d 
and exhibited an overall thickness of about $50-55 \mu \mathrm{m}$. Two more phases were identified in the reaction zones in both tested samples. The phases are identified as anorthite (An) and spinel (Sp) for $65 \mathrm{YZ}$ and GZO, respectively. Figure 4 shows a TEM cross-sectional specimen of a sealed inter-columnar gap in the 65YZ coating. The TEM lamella was cut out of a deeply infiltrated inter-columnar gap after $5 \mathrm{~h}$ of infiltration, which shows the evidence of complete crystallization of the melt into primarily garnet, apatite, and fluorite products at this stage. It is seen that the garnet phase is the main reaction product present in the reaction layer. A higher magnification image (4b) with its respective elemental mappings is provided as well, where the accumulation of $\mathrm{Fe}, \mathrm{Al}$, and $\mathrm{Mg}$ is representative of the garnet phase. The $\mathrm{Zr}$ rich products exhibit the fluorite particles, and the apatite phase is seen as small areas enriched in $\mathrm{Ca}$ at the edges of the inter-columnar gaps. The Ca content is seen to increase in the feather arms showing evidence of apatite formation at these small confined areas. Figure 5 shows the identified SAED patterns for the reaction products seen in the TEM lamella in Figure 4. For the GZO case (Figure 6), the TEM lamella was cut from the top reaction zone of a $10 \mathrm{~h}$ infiltrated sample. The results confirm the formation of a garnet phase (labeled as number 2) as well as intrinsic crystallized diopside (number 1), fluorite (3), and small apatite crystals (A) dispersed with fluorite particles.

\subsubsection{Analysis of the 65YZ/CMAS 1 Reaction layer}

The $65 \mathrm{YZ} / \mathrm{C}_{22} \mathrm{M}_{11} \mathrm{~A}_{20} \mathrm{~S}_{38} \mathrm{~F}_{8} \mathrm{~T}_{1}$ reaction after $50 \mathrm{~h}$ produced a uniform $16 \mu \mathrm{m}$ thick reaction zone consisting mainly of the garnet $(\mathrm{G})$, as shown in Figures 3a and c. A combination of globular fluorite crystals (F) with minimal amounts of confined apatite crystals (A) is seen between the uniform garnet layer and the unreacted coating (Figure 3a). Apparently, the garnet layer is growing at the expense of both fluorite and apatite by perceiving some of these products dispersed inside. Additionally, at the top reaction interface between the glass reservoir and the reaction zone, dark prismatic anorthite (An) crystals are seen distributed along on top of the garnet layer. The observed reaction scenario is similar to that of the previous studies with $65 \mathrm{YZ}$ obtained from two-source evaporation, and even the composition of the reaction products did not change significantly after $5 \mathrm{~min}$ and $20 \mathrm{~h}$ of infiltration tests [17]. The apatite phase (Table 2) exhibits small amounts of $\mathrm{Mg}$ and $\mathrm{Al}$ in solid solution and up to $8.4 \mathrm{~mol} \% \mathrm{Zr}$. The uniform garnet phase shows a higher $\mathrm{CaO}$ content compared to the apatite phase and less $\mathrm{SiO}_{2}$ content, as seen in Table 2. The $\mathrm{YO}_{1.5}$ and $\mathrm{ZrO}$ content has been reduced significantly in the garnet phase compared to the apatite. The small concentration of other cations such as $\mathrm{Mg}, \mathrm{Al}$, and minimal amounts of $\mathrm{Fe}$ in the apatite suggest that the garnet phase uses the apatite crystals as nucleation sites from the interaction of the large glass reservoir with the products promoting their enhanced growth at the expanse of the large glass deposits. Besides, the presence of all cations as well in the fluorite phase in the $65 \mathrm{YZ}$ case also supports the claim that the garnet phase consumes other products.

Inside the inter-columnar gaps, the reaction yielded a combination of apatite, garnet, and fluorite crystals, but did not show traces of anorthite crystals as seen in Figure 3e. The apatite crystals were found as small particles located in small pockets such as feather arms or thin intercolumnar gaps $(1 \mu \mathrm{m}<)$.

\subsubsection{Analysis of the GZO/ CMAS 1 Reaction Layer}


The GZO/C ${ }_{22} \mathrm{M}_{11} \mathrm{~A}_{20} \mathrm{~S}_{38} \mathrm{~F}_{8} \mathrm{~T}_{1}$ reaction layer shown in Figure 3 consists of around $41 \mu \mathrm{m}$ thick layer of uniformly dispersed enlarged faceted apatite crystals mixed with globular fluorite particles (without the garnet layer on top). Compared to the 65YZ, the garnet did not form as a continuous layer, instead it was present as discrete. For these samples with the given microstructure, the GZO layer has produced a larger amount of apatite and fluorite in the reaction zone compared to that of the $65 \mathrm{YZ}$ layer. This is evident by comparing the $41 \mu \mathrm{m}$ thick layer of GZO with the $5 \mu \mathrm{m}$ thick apatite layer located below the $11 \mu \mathrm{m}$ continuous garnet in the $65 \mathrm{YZ}$.

The garnet layer also exhibits the same engulfing behavior seemingly related to grow on top of the apatite and fluorite in a non-continuous irregular layer. Additionally, a FeO rich spinel phase was found in this reaction layer, appearing as small prismatic dark crystals dispersed through all the reaction layer, especially in the large intercolumnar gaps. A similar, however, FeO-free spinel-type phase was reported previously in the literature [14]. The apatite phase does not contain $\mathrm{MgO}$ or $\mathrm{AlO}_{1.5}$ and contains less $\mathrm{ZrO}_{2}$ compared to the $65 \mathrm{YZ}$ case. The phase equilibria will be discussed later. The fluorite phase exhibits a higher $\mathrm{ZrO}_{2}$ content and fewer impurities such as $\mathrm{Mg}$, Al, and Si compared to the $65 \mathrm{YZ}$ fluorite case. The garnet phase also holds all available cations, in particular, the same $\mathrm{FeO}$ enrichment similar to $65 \mathrm{YZ}$ coating. Small amounts of unreacted glass/residue were found on top of the reaction layers without garnet crystals.

The reaction products in the inter-columnar gaps were found to be a mixture of all the possible phases, i.e., spinel, garnet, apatite, and fluorite, as seen in Figure 3e. The garnet phase also appears to engulf other small products, as observed in the reaction layer. In contrary to the $65 \mathrm{YZ}$ case, the apatite crystals are predominantly dispersed inside large inter-columnar gaps instead as in small confined pockets and feather arms as exhibited for the $65 \mathrm{YZ}$ case. Finally, it is seen that spinel, and occasionally garnets were formed inside large inter-columnar gaps.

\subsection{Complementary Infiltration Experiments with Other CMAS Sources}

As stated before, other CMAS sources were tested, but the majority of the experiments focused on the $\mathrm{C}_{22} \mathrm{M}_{11} \mathrm{~A}_{20} \mathrm{~S}_{38} \mathrm{~F}_{8} \mathrm{~T}_{1}$ composition. The following results are provided to show the difference in the reaction layer with different CMAS sources infiltrating 65YZ and GZO. Besides, the difference in infiltration depth is provided. The infiltration experiments performed for $65 \mathrm{YZ}$ samples exhibited less infiltration and thinner reaction layer than GZO, as shown in Figure 7, most probably due to the smaller intercolumnar gaps in $65 \mathrm{YZ}$. The overall infiltration zone is delimited within the dotted lines. Therefore, it is clearly seen that infiltration depth in $65 \mathrm{YZ}$ samples was $55.5 \pm 8.2,50.5 \pm 4.1$, and $53 \pm 4.8 \mu \mathrm{m}$ for the Iceland volcanic ash $\left(\mathrm{C}_{11} \mathrm{M}_{6} \mathrm{~A}_{13} \mathrm{~S}_{45} \mathrm{~F}_{16} \mathrm{~T}_{4} \mathrm{~L}_{5}\right)$, UCSB CMAS $\left(\mathrm{C}_{33} \mathrm{M}_{9} \mathrm{~A}_{13} \mathrm{~S}_{45}\right)$, and CMAS $2\left(\mathrm{C}_{28} \mathrm{M}_{10} \mathrm{~A}_{18} \mathrm{~S}_{35} \mathrm{~F}_{7} \mathrm{~T}_{1}\right)$, respectively. For the GZO case, the infiltration depth was found to be $80 \pm 8,147 \pm 17$, and 168 $\pm 30 \mu \mathrm{m}$, respectively. However, it is essential to note that the porosity and the morphology in both coatings are different.

The main reaction product found for the $65 \mathrm{YZ} / \mathrm{C}_{28} \mathrm{M}_{10} \mathrm{~A}_{18} \mathrm{~S}_{35} \mathrm{~F}_{7} \mathrm{~T}_{1}$ (Figure 7a) reactions was still the Fe-bearing garnet phase $(\mathrm{G})$. The apatite phase (A) was found to be distributed uniformly 
under the garnet layer along with small fluorite crystals. In the case of GZO (Figure 7b) also a continuous garnet layer has formed at the reaction front, separating the glass and the coating. A mixed layer of apatite and fluorite products lay underneath the garnet phase.

The $\mathrm{C}_{33} \mathrm{M}_{9} \mathrm{~A}_{13} \mathrm{~S}_{45}$ interactions with $65 \mathrm{YZ}$ (Figure $7 \mathrm{~b}$ ) showed lower amounts of garnet phase only as localized products in the glass at the interface with the coating. It is important to note that even without Fe presence in this CMAS compound, the garnet phase was still promoted. The apatite phase precipitated here as enlarged facets protruding out from the coating into the glass. The GZO coating showed a layer of mixed apatite and fluorite phases throughout the coating (Figure 7e). Conversely, the garnet phase was not promoted during interactions with $\mathrm{C}_{33} \mathrm{M}_{9} \mathrm{~A}_{13} \mathrm{~S}_{45}$. Lastly, the $\mathrm{C}_{11} \mathrm{M}_{6} \mathrm{~A}_{13} \mathrm{~S}_{45} \mathrm{~F}_{16} \mathrm{~T}_{4} \mathrm{~L}_{5}$ reactions showed a wide variety of reaction products for both coatings. In the $65 \mathrm{YZ}$ case (Figure 7c), the apatite, Fe-garnet, and fluorite are still present in the reaction. The zirconolite layer $(\mathrm{Z})$ was found here with high amounts of $\mathrm{Fe}$ and Ti lying at the top of the reaction layer. This phase was found as well in previous experiments for infiltration times with $\mathrm{C}_{11} \mathrm{M}_{6} \mathrm{~A}_{13} \mathrm{~S}_{45} \mathrm{~F}_{16} \mathrm{~T}_{4} \mathrm{~L}_{5}$ (Iceland volcanic ash) and $65 \mathrm{YZ}$ for times from 5 min up to $20 \mathrm{~h}[17,27]$. The GZO case (Figure 7f) shows a very uniform reaction layer, which almost extends the same depth as the infiltration zone. On the top of the layer, localized zirconolite particles (about $5 \mu \mathrm{m}$ long) are distributed throughout the coating. The zirconolite phase has been found as well in such long term interactions $(100 \mathrm{~h})$ with volcanic ash for GZO in the literature [16]. The reaction layer mostly carries distributed/mixed apatite and fluorite phases that extend along with the whole coating. Additionally, small localized spinel crystals are also present in this reaction, as exhibited for the $\mathrm{C}_{22} \mathrm{M}_{11} \mathrm{~A}_{20} \mathrm{~S}_{38} \mathrm{~F}_{8} \mathrm{~T}_{1}$ case. The summary of reaction product composition is provided below in Table $\mathbf{3}$ for all $65 \mathrm{YZ} / \mathrm{GZO}$ tests.

\section{Discussion}

It is well known that effective CMAS infiltration mitigation by any TBC is highly dependent on the composition of the local CMAS melt and the reactivity of the TBC oxide components available to saturate the CMAS melt, thereby promoting its crystallization. Additionally, the crystalline reaction products should be able to effectively seal the inter-columnar gaps preventing further melt infiltration of the TBC over long periods. Thus, microstructural aspects, primarily the width of the intercolumnar gaps, also play a significant role in the CMAS resistance driven by the ability to seal infiltration channels with crystalline reaction products. In this particular study, the crystalline reaction products are clearly distinct depending on the employed reactive oxide in the TBC, i.e., $\mathrm{GdO}_{1.5}$ or $\mathrm{YO}_{1.5}$. As for the coatings used in this study, the $65 \mathrm{YZ}$ has shown better infiltration resistance and the thinner reaction layer compared to the GZO coating. It is believed that three main mechanisms are differentiating the infiltration and reaction behavior of the two TBCs. These mechanisms represent a) The kinetics of phase formation, which influences fast glass crystallization and slow reaction layer growth, b) the microstructure of the coating, and c) the viscosity of the CMAS melt related to the dissolved cation, which controls the wettability of the fluid and ultimately its infiltration depth.

\subsection{Reaction kinetics}


From the reaction scenario observed within the inter-columnar gaps, it can be concluded that the first reaction products to form upon reaching the local saturation limit in the melt are the apatite and fluorite phases for both TBCs. The apatite phase is believed to be the most beneficial phase to promote CMAS crystallization during the initial infiltration stages since it is the most energetically favorable silicate phase to form upon reaching RE saturation in the CMAS melt [9]. As $\mathrm{Zr}^{4+}$ exhibits about two times lower solubility than $\mathrm{Y}^{3+}$ [28], it quickly re-precipitates as fluorite type phase retaining some $\mathrm{YO}_{1.5}$ or $\mathrm{GdO}_{1.5}$ and probably $\mathrm{CaO}$, which can also act as a stabilizer $[13,16]$. The current results indicate that the garnet phases are forming, preferably in areas where the local melt composition is rich in $\mathrm{MgO}$ and $\mathrm{FeO}$ (mainly in large inter-columnar gaps or close to the CMAS melt reservoir) where the small apatite crystals trigger nucleation. This conclusion is driven from the observation that the nucleated garnet phases are only found in large inter-columnar gaps and at the reaction layer, which can accumulate enough glass to shift the reaction. The apatite and spinel crystals formed at the reaction layer are believed to be the first products of the melt crystallization. Anorthite has been identified along with pyroxene $(\mathrm{Ca}, \mathrm{Mg}, \mathrm{Fe}, \mathrm{Al}, \mathrm{Ti})(\mathrm{Si}, \mathrm{Al})_{2} \mathrm{O}_{6}$ in heat treatment experiments of the pure $\mathrm{C}_{22} \mathrm{M}_{11} \mathrm{~A}_{20} \mathrm{~S}_{38} \mathrm{~F}_{8} \mathrm{~T}_{1}$ powder [24]. On the other hand, the spinel phase, which is found in GZO, is believed to form if the melt is locally depleted in $\mathrm{SiO}_{2}$ and $\mathrm{CaO}$. This is promoted when apatite formation leaves $\mathrm{Al}, \mathrm{Mg}$, and Fe enriched melt that subsequently crystallizes as Fe rich spinel. This spinel phase is not found in the $65 \mathrm{YZ}$ sample. A possible explanation is the higher preference of $65 \mathrm{YZ}$ to form Fe rich garnet, which consumes all available $\mathrm{Mg}, \mathrm{Al}$, and $\mathrm{Fe}$, as explained in the next sections.

It is currently not known whether the garnet phase is beneficial for significant CMAS arrest due to its slower nucleation rate compared to apatite or not. Evidence of garnet formation for $\mathrm{Fe}$ carrying CMAS sources has been shown already by the infiltration studies for short periods of $5 \mathrm{~min}$ at $1250^{\circ} \mathrm{C}$ [17]. The current study shows an extensive garnet formation for $65 \mathrm{YZ} \mathrm{TBC}$ forming a uniform continuous reaction layer throughout the coating. On the other hand, large localized garnet areas were identified in the GZO TBC. It was reported in the literature that the increased tendency of garnet formation for smaller $\mathrm{RE}$ cations such as $\mathrm{Yb}^{3+}$ or $\mathrm{Y}^{3+}$ is due to the higher partition coefficient generated for these products compared to larger RE cations such as $\mathrm{Gd}^{3+}$ and $\mathrm{La}^{3+}$ [29]. The partition coefficient is defined as the concentration of a specific compound in two phases that are in equilibrium [29, 30]. Also, the formation enthalpy of the apatite phase has been reported to decrease for smaller RE cations making them less stable [29, 31]. Figure 8 shows the partition coefficient (D) plot of garnet and apatite compared to the literature values taken from [29]. The results are in good agreement showing the GZO garnet $\left(\mathrm{D}_{\mathrm{GGZO}}=3.5\right)$ close to the upper limit reported in the literature, confirming the propensity of Gdgarnet phase formation by reaction of $\mathrm{GZO}$ with $\mathrm{C}_{22} \mathrm{M}_{11} \mathrm{~A}_{20} \mathrm{~S}_{38} \mathrm{~F}_{8} \mathrm{~T}_{1}$ melts. The plot also confirms the higher preference of garnet formation linked to a higher $\mathrm{D}$ value $\left(\mathrm{D}_{\mathrm{G} 65 \mathrm{YZ}}=4.5\right)$ for the $65 \mathrm{YZ}$ samples as expected from these infiltration results.

Conversely, the plot for the apatite phase exhibits a larger coefficient of the 65YZ apatite $\left(D_{A 65 Y Z}=11.6\right)$ compared to the $\mathrm{GZO}\left(\mathrm{G}_{\mathrm{AGZO}}=10.3\right)$, predicting a higher preference of apatite formation for the $65 \mathrm{YZ}$ sample. The found partition coefficient data is not in agreement with the literature reports that show claim that, GZO has a higher apatite crystallization potential than $\delta-\mathrm{Y}_{3} \mathrm{Zr}_{2} \mathrm{O}_{12}[9,29,32]$. In the context of the garnet phase, it also important to highlight that 
the garnet formation retains a lower amount of $\mathrm{RE}+\mathrm{ZrO}_{2}(18.3 \%$ and $23.1 \%$ for $65 \mathrm{YZ}$ and GZO, respectively) than the apatite phase ( $51.3 \%$ and $53.6 \%$ for $65 \mathrm{YZ}$ and GZO respectively). This implies that the garnet formation consumes much less coating material to crystallize equal amounts of the CMAS melt than the apatite phase. Moreover, it can retain a larger variety of cations instead of only $\mathrm{Ca}$ and $\mathrm{Si}$ as for apatite. Therefore, the $65 \mathrm{YZ}$ sample, which promotes garnet formation, exhibits less infiltration and thinner reaction layers than the GZO counterpart/version. This leads to the conclusion that for long term infiltration, the garnet phase may be beneficial since its slower reaction rate could lead to less coating consumption.

The rapid apatite phase formation is vital in the initial stages of infiltration because it provides (partial) crystallization of the CMAS melt instantaneously. The Ca solubility limit for the apatite phase is dictated by the formula $\mathrm{M}_{4}^{\mathrm{I}} \mathrm{M}^{\mathrm{II}}{ }_{6}\left(\mathrm{SiO}_{4}\right)_{6} \mathrm{X}$ where the $\mathrm{Ca}^{2+}$ and $\mathrm{Mg}^{2+}$ are assumed to occupy only the $\mathrm{M}^{\mathrm{I}}$ site. The $\mathrm{RE}^{3+}$ cation is reported to be accommodated in the $\mathrm{M}^{\mathrm{I}}$ and $\mathrm{M}^{\mathrm{II}}$ sites [33-38], and $\mathrm{X}$ represents the oxygen anion. $\mathrm{Zr}^{4+}$ is believed to occupy the $\mathrm{M}^{\mathrm{II}}$ site along with $\mathrm{RE}^{3+}$ [9]. Finally, $\mathrm{Al}^{3+}$ in the apatite is believed to be accommodated in the $\mathrm{Si}^{4+}$ tetrahedra [16]. The so-called precipitation ratio represents a way to predict how much coating is consumed to apatite, i.e., the higher the $\mathrm{M}^{\mathrm{I}}: \mathrm{M}^{\mathrm{II}}$ ratio, the fewer amount of coating is consumed [29].

In this context, the most effective apatite would be the theoretical $\mathrm{M}_{4}^{\mathrm{I}} \mathrm{M}_{6}{ }_{6}\left(\mathrm{SiO}_{4}\right)_{6} \mathrm{X}$ phase, which gives the maximum possible ratio of 0.66, as seen in Figure 9. An estimation is made by comparing the ratio of the $\mathrm{M}^{\mathrm{I}}: \mathrm{M}^{\mathrm{II}}$ sites compositions $\left.((\mathrm{RE}+\mathrm{Ca}+\mathrm{Mg}) /(\mathrm{RE}+\mathrm{Zr}))\right)$ modified from studies performed by Poerschke et al. [29]. For the calculations in this study, the $\mathrm{RE}^{3+}$ cation is assumed to take only the $\mathrm{M}^{\mathrm{II}}$-site. The apatite phases at the reaction zone showed a precipitation ratio of 0.32 and 0.27 for $65 \mathrm{YZ}$ and GZO in case of CMAS1, respectively. These ratios are closer to the $\mathrm{M}_{2}^{\mathrm{I}} \mathrm{M}^{\mathrm{II}}{ }_{8}\left(\mathrm{SiO}_{4}\right)_{6} \mathrm{O}_{2}$ apatite phase $(0.25)$, as seen in Figure 9. Furthermore, the provided plot includes the apatite ratio estimations from the complementary experiments using CMAS 2, USCB, and Iceland VA, as specified in Table 4. For this specific experimental case (after $50 \mathrm{~h}$ at $1250^{\circ} \mathrm{C}$ ), it is seen that the $65 \mathrm{YZ}$ coating was able to promote apatite phases with a higher $\mathrm{M}^{\mathrm{I}}: \mathrm{M}^{\mathrm{II}}$ ratio (Figure 9) which leads to the conclusion that $\mathrm{Y}$ based apatite requires less TBC material for its formation. Hence the consumption of $\mathrm{Y}$ would be less. A similar study comparing $\mathrm{GZO}$ and $\mathrm{Y}_{2} \mathrm{Zr}_{2} \mathrm{O}_{7}$ pellets under CMAS attack at $1200^{\circ} \mathrm{C}$ for $24 \mathrm{~h}$ was performed by Drexler et al. [35]. Their results also showed less CMAS infiltration even with the lower $Y$ containing $\mathrm{Y}_{2} \mathrm{Zr}_{2} \mathrm{O}_{7}$ pellet. They have concluded that the larger $\mathrm{Gd}^{3+}$ cation would have a higher tendency to occupy also the $\mathrm{M}^{\mathrm{I}}$ site which increases the amount of Gd needed to promote apatite formation. In contrary, the smaller $\mathrm{Y}^{3+}$ cation appears to preferentially occupy the $\mathrm{M}^{\mathrm{II}}$ site which allows more cations to fill more efficiently the $\mathrm{M}^{\mathrm{I}}$ site such as $\mathrm{Mg}$, Ca. This hypothesis is supported by the absence of $\mathrm{Mg}$ in the GZO apatite for these specific studies. One final remark is that the $\mathrm{Zr}$ content in the $65 \mathrm{YZ}$ apatite is higher compared to the $\mathrm{GZO}$ which might reduce the amount of RE that is consumed in the apatite phase since $\mathrm{Zr}$ occupies the $\mathrm{M}^{\mathrm{II}}$ which in theory would otherwise consume mostly the RE cation.

\subsection{Microstructural effect}

Apart from the different rare earth cations used in the coatings, the infiltration and reaction kinetics were also strongly influenced by the microstructure, which therefore needs to be 
considered when discussing their CMAS resistance. From Table 1, it can be seen that the intercolumnar gap width in the GZO coating is almost double to that of 65YZ. Even though GZO is known for its quick apatite formation upon CMAS reaction, the gaps were too large to seal them completely, which allowed the CMAS glass to infiltrate deeper. The 65YZ coating with smaller inter-columnar gaps exhibited an overall $\mathrm{C}_{22} \mathrm{M}_{11} \mathrm{~A}_{20} \mathrm{~S}_{38} \mathrm{~F}_{8} \mathrm{~T}_{1}$ infiltration depth of $58 \pm 5 \mu \mathrm{m}$ $\begin{array}{lllllll}\text { compared } & \text { to } & 150 & \pm 20 & \mu \mathrm{m} & \text { in } & \text { GZO. }\end{array}$ The presence of larger amounts of CMAS on top of $65 \mathrm{YZ}$ compared to that of GZO coating proves the fact that smaller gaps were quickly sealed and restricted CMAS further infiltration. This microstructural effect was also observed in EB-PVD 65YZ coating, where a jumping beam on a dual evaporation source (100\% yttria and 7YSZ) was used to create the 65YZ composition. The microstructure was found to be non-uniform with larger gaps $(>2 \mu \mathrm{m})$ and has resulted in higher infiltration depth compared to the current $65 \mathrm{YZ}$ coating, which was coated by using a single evaporation source [17]. The larger gaps could also influence the reaction product formation. Presumably, the garnet forms in larger gaps where enough $\mathrm{FeO}$ and $\mathrm{TiO}_{2}$ enriched melt is available. This is evident in the case of CMAS 1(see Fig.3\&4), where garnet was found in larger pockets whereas apatite was found at the smaller inter-columnar gaps (both in GZO and $65 \mathrm{YZ}$ coatings). These findings are in agreement with yttria rich zirconia powder studies from Krause et al., where they reported the apatite formation in confined pocket spaces [28]. In these small confined areas, the CMAS melt quickly reaches the $\mathrm{Y}^{3+}$ saturation limit, which promotes apatite crystallization. The garnet phase was found in large inter-columnar gaps where more glass is available and appears to engulf the apatite and fluorite crystals. This finding is consistent with the reports in the literature that the garnet phase emerges as a secondary reaction product with a slower precipitation rate compared to apatite [9, 29, 32, 39].

With the samples used in this study, it is challenging to determine the influence of the microstructure on the diverging CMAS resistance compared to the impact of the different RE-elements employed in the TBC. Further studies with various microstructures of the same coating material need to be conducted to distinguish more profoundly the effect of this to factors and to rule out the influence of morphology.

\subsection{Viscosity effect}

The influence of the amount of dissolved RE on CMAS melt viscosity also plays an essential role in infiltration. Assuming that there is no reaction between both TBCs and the CMAS melt, the $65 \mathrm{YZ}$ samples would be expected to be more infiltrated since it exhibited the higher porosity compared (20.5\%) to the GZO samples (19.2\%). However, due to the dissolution of the TBC material into the melt, it is expected that the melt composition changes as it gets enriched with $\mathrm{RE}^{3+}$ and $\mathrm{Zr}^{4+}$. From the literature, it is known that the dissolution of $\mathrm{Y}^{3+}$ and $\mathrm{Gd}^{3+}$ into glass melts reduces the melt viscosity, whereas $\mathrm{Zr}^{4+}$ increases the viscosity [32, 35, 40, 41]. Then, $\mathrm{Gd}^{3+}$ is known to reduce viscosity more effectively than $\mathrm{Y}^{3+}[35,42]$. Furthermore, new viscosity studies performed by Müller et al. [42] have shown a change of viscosity of about $0.94 \mathrm{~Pa}$ s for YSZ and $0.75 \mathrm{~Pa}$ s for GZO in high temperature rheological studies with Krafla volcanic ash with the same amount of solute doping of $1 \mathrm{~mol} \%$. The studies also show more volcanic ash mixtures with GZO and YSZ doping in volcanic ash melts at different concentrations but their change in viscosity was extrapolated assuming a first order linear 
relationship. In all extrapolation cases the GZO doped melts showed a smaller reduction is viscosity compared with YSZ for the same extrapolated amount of dopant supporting the claim that GZO dissolution could lead to higher melt spreading due to the smaller reduction in viscosity. Crystallization of GZO based apatite appears to require more RE dissolution than its $65 \mathrm{YZ}$ counterpart. For that reason, it is expected that the melt viscosity drops more in the case of GZO, producing a deeper infiltration. Additionally, the lower viscosity of the melt should enhance the infiltration of the nanoporous features of the coatings, thereby dissolving more coating material and forming more reaction products. This assumption is in agreement with the significantly larger reaction zone observed in the GZO case.

\section{Conclusions}

$65 \mathrm{YZ}$ and GZO based EB-PVD TBCs with different thicknesses and similar overall thickness were exposed to $\mathrm{C}_{22} \mathrm{M}_{11} \mathrm{~A}_{20} \mathrm{~S}_{38} \mathrm{~F}_{8} \mathrm{~T}_{1}$ melt at $1250^{\circ} \mathrm{C}$ for up to $50 \mathrm{~h}$. Both coatings reacted with the CMAS vigorously and produce apatite, $\mathrm{Fe}$ rich garnet, and fluorite phases. Two different phases were also observed in the coatings: Anorthite for the $65 \mathrm{YZ}$ case and Fe rich spinel for GZO. Anorthite appears to crystallize mostly in the non-infiltrated CMAS melt. In contrast, the spinel phase seems to form within the inter-columnar gaps where melts are locally enriched in $\mathrm{Al}, \mathrm{Mg}$, and Fe due to the apatite formation. The infiltration behavior differed for the two coatings used in this study. The $65 \mathrm{YZ}$ coating exhibited higher infiltration resistance and thinner reaction zones compared to the GZO, which, however, could also be linked to the different microstructures. The reaction mechanisms were studied in the light of the crystallization of beneficial crystalline phases such as apatite and garnet and the viscosity effects. The following conclusions can be drawn from this study:

- Different complex synergetic reactions promote apatite and garnet formation at different rates for both TBC types.

- Based on the partition coefficient calculations at the CMAS-TBC-interface, the $65 \mathrm{YZ}$ coatings were found to be more effective in forming the apatite phase by consuming less coating material and more CMAS products compared to GZO cases.

- The formation of a continuous garnet as a secondary phase at the interface was found to crystallize slower but consume larger quantities of CMAS products, which crystallize more glass volume and reduces the infiltration.

- The morphology of the coating affects the CMAS infiltration and reaction kinetics significantly. The intercolumnar gap width plays a vital role in the extent of the infiltration and the formation of CMAS blocking reaction products.

- The contribution of the microstructural differences to the different CMAS resistance compared to that of the different RE-element needs to be analyzed in subsequent studies. Samples with similar microstructures would allow to rule out these factors to determine more precisely the influence of the RE-element in the TBC material for the CMAS resistance.

\section{Acknowledgments}

The authors thank Mr. D. Peters, Mr. J. Brien, and Mr. A. Handwerk, for their assistance in the EB-PVD sample deposition and infiltration testing. The authors also acknowledge Mr. F. Kreps for his assistance in the FIB preparation. The authors thank the Consejo Nacional de Ciencia y Tecnologia (CONACYT) for providing financial support. The authors also acknowledge the 
German Science Foundation (DFG) for providing financial support to this work under grant no SCHU 1372/5-1.

\section{References}

1. Padture, N.P., M. Gell, and E.H. Jordan, Thermal Barrier Coatings for Gas Turbine Engine Applications. Science, 2002. 296: p. 280-284.

2. Schulz, U., et al., Review on Advanced EB-PVD Ceramic Topcoats for TBC Applications. International Journal of Applied Ceramic Technology, 2005. 1: p. 302-315.

3. Darolia, R., Thermal barrier coatings technology: critical review, progress update, remaining challenges and prospects. International Materials Reviews, 2013. 58: p. 315-348.

4. Evans, A.G., D.R. Clarke, and C.G. Levi, The influence of oxides on the performance of advanced gas turbines. Journal of the European Ceramic Society, 2008. 28: p. 1405-1419.

5. Padture, N.P., Advanced structural ceramics in aerospace propulsion. Nature Materials, 2016. 15: p. 804-809.

6. Clarke, D.R., M. Oechsner, and N.P. Padture, Thermal-barrier coatings for more efficient gasturbine engines. MRS Bulletin, 2012. 37: p. 891-898.

7. Sampath, S., et al., Processing science of advanced thermal-barrier systems. MRS bulletin, 2012. 37: p. 903-910.

8. Levi, C.G., et al., Environmental degradation of thermal-barrier coatings by molten deposits. MRS Bulletin, 2012. 37: p. 932-941.

9. Poerschke, D.L., R.W. Jackson, and C.G. Levi, Silicate Deposit Degradation of Engineered Coatings in Gas Turbines: Progress Toward Models and Materials Solutions. Annual Review of Materials Research, 2017. 47(1): p. 297-330.

10. Mercer, C., et al., A delamination mechanism for thermal barrier coatings subject to calciummagnesium-alumino-silicate (CMAS) infiltration. Acta Materialia, 2005. 53: p. 1029-1039.

11. Drexler, J.M., et al., Jet engine coatings for resisting volcanic ash damage. Advanced Materials, 2011. 23: p. 2419-2424.

12. Drexler, J.M., et al., Plasma sprayed gadolinium zirconate thermal barrier coatings that are resistant to damage by molten $\mathrm{Ca}-\mathrm{Mg}-\mathrm{Al}$-silicate glass. Surface and Coatings Technology, 2012. 206: p. 3911-3916.

13. Eils, N.K., P. Mechnich, and W. Braue, Effect of CMAS Deposits on MOCVD Coatings in the System Y2O3-ZrO2: Phase Relationships. Journal of the American Ceramic Society, 2013. 96: p. 3333-3340.

14. Krämer, S., J. Yang, and C.G. Levi, Infiltration-inhibiting reaction of gadolinium zirconate thermal barrier coatings with CMAS melts. Journal of the American Ceramic Society, 2008. 91: p. 576-583.

15. Krause, A.R., et al., 2ZrO2-Y2O3 thermal barrier coatings resistant to degradation by molten CMAS: Part II, Interactions with sand and fly ash. Journal of the American Ceramic Society, 2014. 97: p. 3950-3957.

16. Mechnich, P. and W. Braue, Volcanic ash-induced decomposition of EB-PVD Gd 2 Zr 207 thermal barrier coatings to Gd-oxyapatite, zircon, and Gd, Fe-zirconolite. Journal of the American Ceramic Society, 2013. 96: p. 1958-1965.

17. Naraparaju, R., et al., Interaction and infiltration behavior of Eyjafjallajökull, Sakurajima volcanic ashes and a synthetic CMAS containing FeO with/in EB-PVD ZrO2-65 wt\% Y2 O3 coating at high temperature. Acta Materialia, 2017. 136: p. 164-180.

18. Poerschke, D.L., et al., Stability and CMAS Resistance of Ytterbium-Silicate/Hafnate EBCS/TBC for SiC Composites. Journal of the American Ceramic Society, 2015. 98(1): p. 278-286.

19. Schulz, U. and W. Braue, Degradation of La2Zr2O7 and other novel EB-PVD thermal barrier coatings by CMAS (CaO-MgO-Al2O3-SiO2) and volcanic ash deposits. Surface and Coatings Technology, 2013. 235: p. 165-173. 
20. Drexler, J.M., et al., Air-plasma-sprayed thermal barrier coatings that are resistant to hightemperature attack by glassy deposits. Acta Materialia, 2010. 58: p. 6835-6844.

21. Naraparaju, R., et al., Estimation of CMAS Infiltration depth in EB-PVD TBCs: A new constraint model supported with experimental approach. Journal of the European Ceramic Society, 2019.

22. Naraparaju, R., et al., Tailoring the EB-PVD columnar microstructure to mitigate the infiltration of CMAS in 7YSZ thermal barrier coatings. Journal of the European Ceramic Society, 2017. 37 : p. 261-270.

23. Naraparaju, R., et al., The Accelerating Effect of CaSO sub4sub Within CMAS (CaO-MgO-Al sub2sub O sub3sub -SiO sub2sub) and Its Effe. Journal of the American Ceramic Society Ceramic Society, 2016. 99: p. 1398-1403.

24. Naraparaju, R., et al., Degradation study of 7wt.\% yttria stabilised zirconia (7YSZ) thermal barrier coatings on aero-engine combustion chamber parts due to infiltration by different $\mathrm{CaO}$ MgO-Al2O3-SiO2 variants. Surface and Coatings Technology, 2014. 260: p. 73-81.

25. Renteria, A.F., et al., Effect of morphology on thermal conductivity of EB-PVD PYSZ TBCs. Surface and Coatings Technology, 2006. 201: p. 2611-2620.

26. Schulz, U., H. Oettel, and W. Bunk, Texture of EB-PVD thermal barrier coatings under variable deposition conditions. Zeitschrift für Metallkunde, 1996. 87(6): p. 488-492.

27. Chavez, J.J.G., et al., Effects of yttria content on the CMAS infiltration resistance of yttria stabilized thermal barrier coatings system. Journal of Materials Science \& Technology, 2019.

28. Krause, A.R., X. Li, and N.P. Padture, Interaction between ceramic powder and molten calciamagnesia-alumino-silicate (CMAS) glass, and its implication on CMAS-resistant thermal barrier coatings. Scripta Materialia, 2016. 112: p. 118-122.

29. Poerschke, D.L. and C.G. Levi, Effects of cation substitution and temperature on the interaction between thermal barrier oxides and molten CMAS. Journal of the European Ceramic Society, 2015. 35(2): p. 681-691.

30. Speight, J.G., Chapter 6 - Introduction Into the Environment, in Environmental Organic Chemistry for Engineers, J.G. Speight, Editor. 2017, Butterworth-Heinemann. p. 263-303.

31. Risbud, A.S., et al., Enthalpies of formation of lanthanide oxyapatite phases. Journal of Materials Research, 2001. 16: p. 2780-2783.

32. Poerschke, D.L., T.L. Barth, and C.G. Levi, Equilibrium relationships between thermal barrier oxides and silicate melts. Acta Materialia, 2016. 120: p. 302-314.

33. Shannon, R., Revised effective ionic radii and systematic studies of interatomic distances in halides and chalcogenides. Acta Crystallographica Section A, 1976. 32: p. 751-767.

34. Shannon, R.D.T. and C.T. Prewitt, Effective ionic radii in oxides and fluorides. Acta Crystallographica Section B: Structural Crystallography and Crystal Chemistry, 1969. 25: p. 925946.

35. Drexler, J.M., A.L. Ortiz, and N.P. Padture, Composition effects of thermal barrier coating ceramics on their interaction with molten Ca-Mg-Al-silicate (CMAS) glass. Acta Materialia, 2012. 60: p. 5437-5447.

36. Ito, J., Silicate apatites and oxyapatites. American Mineralogist, 1968. 53(5-6): p. 890-907.

37. Poerschke, D.L., et al., Phase equilibria and crystal chemistry in the calcia-silica-yttria system. Journal of the European Ceramic Society, 2016. 36(7): p. 1743-1754.

38. Felsche, J., Rare earth silicates with the apatite structure. Journal of Solid State Chemistry, 1972. 5: p. 266-275.

39. Poerschke, D.L., G.G.E. Seward, and C.G. Levi, Influence of Yb:Hf Ratio on Ytterbium Hafnate/Molten Silicate (CMAS) Reactivity. Journal of the American Ceramic Society, 2016. 99(2): p. 651-659.

40. Fluegel, A., Glass viscosity calculation based on a global statistical modelling approach. Glass Technology-European Journal of Glass Science and Technology Part A, 2007. 48(1): p. 13-30.

41. Wang, M., et al., Viscosity and thermal expansion of soda-lime-silica glass doped with Gd2O3 and Y2O3. Solid State Sciences, 2012. 14(8): p. 1233-1237. 
42. Müller, D., et al., Effects of the dissolution of thermal barrier coating materials on the viscosity of remelted volcanic ash. American Mineralogist: Journal of Earth and Planetary Materials, 2020. 105(7): p. 1104-1107.

Figures and Tables

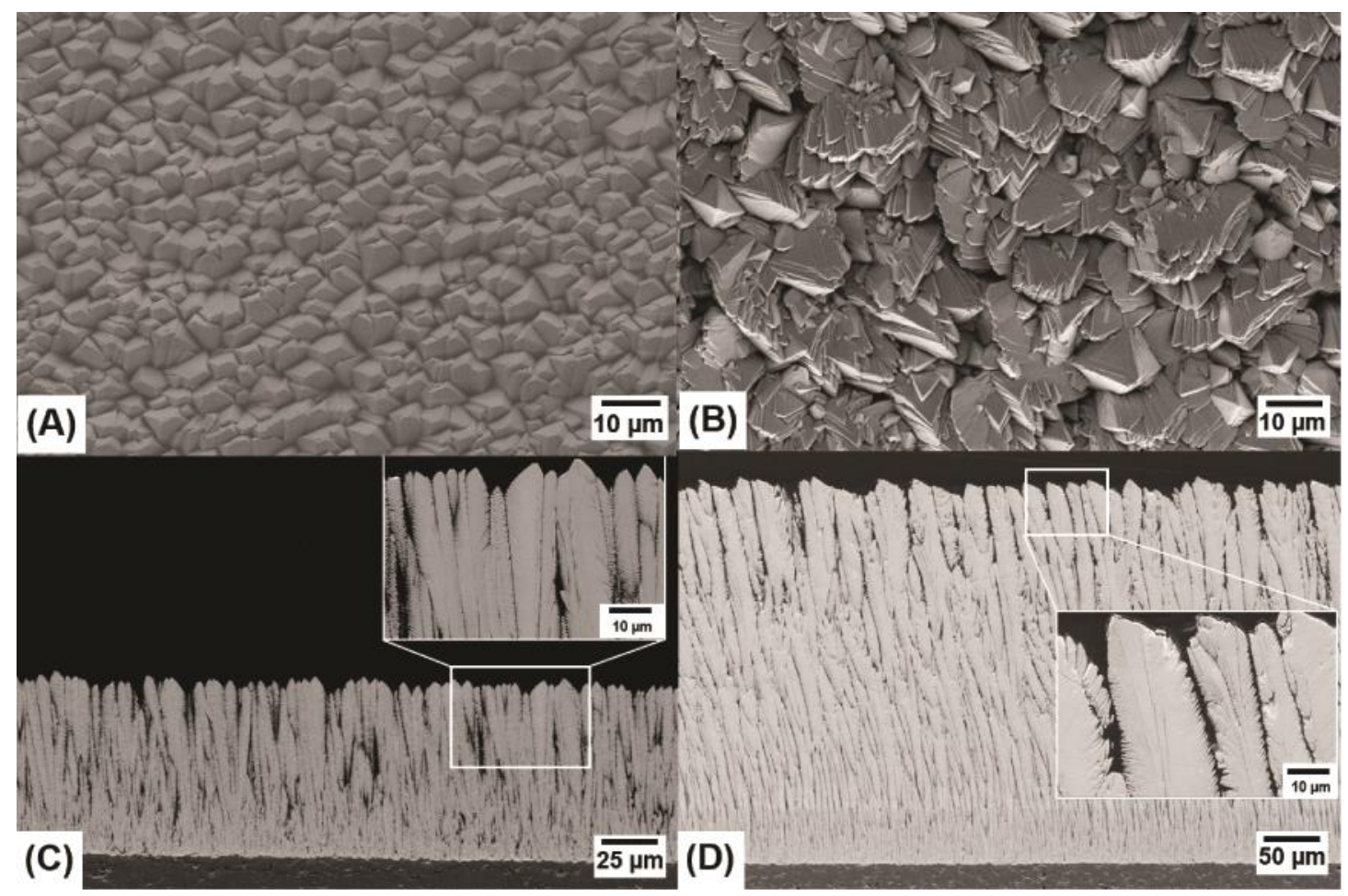

Figure 1: SEM cross-section and top view images of the as coated on alumina substrates: $65 Y Z$ samples $(A$ and $C)$ and the $G Z O$ samples $(B$ and $D)$. 


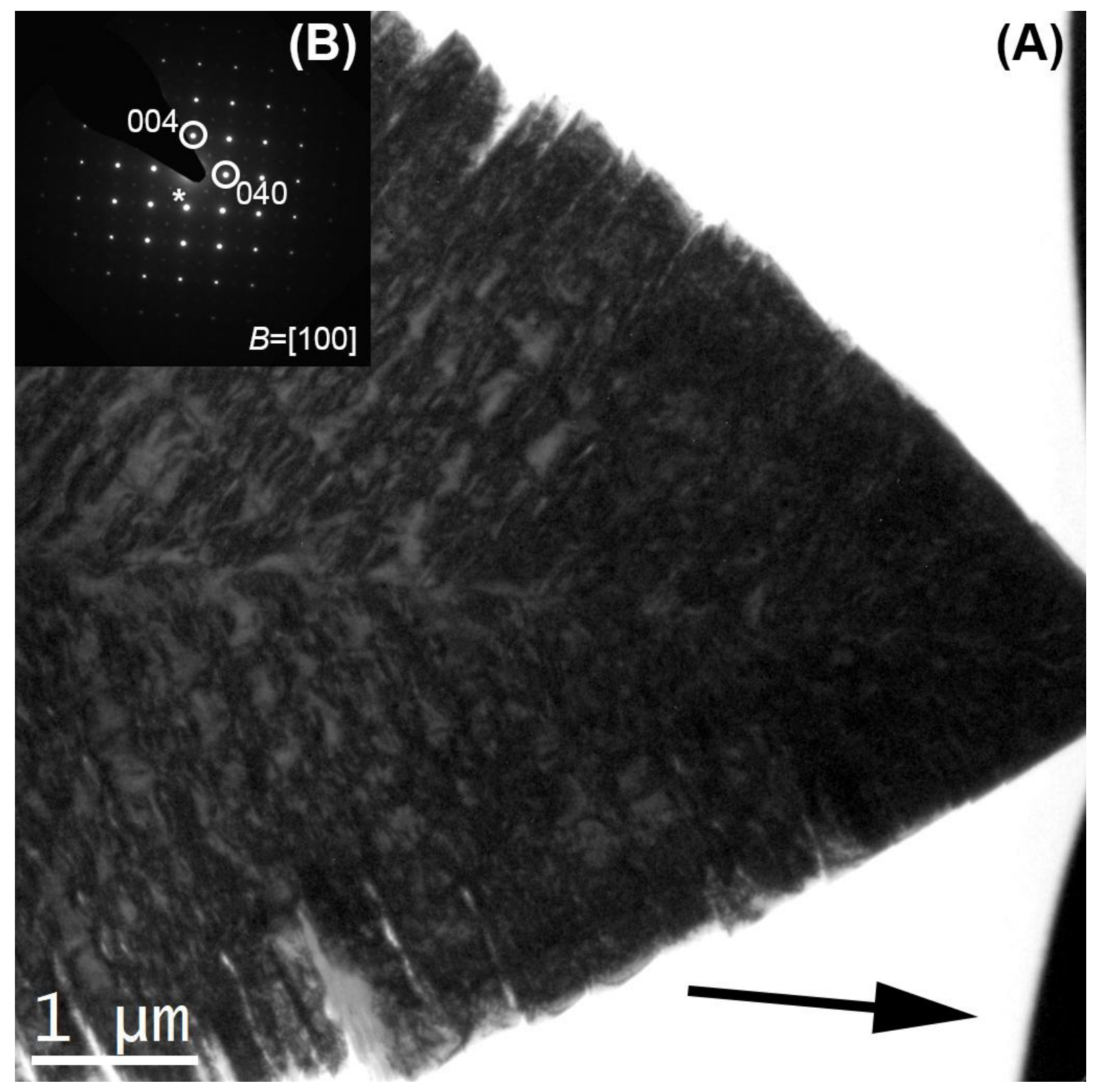

Figure 2: (A) Darkfield TEM image of the as coated top TBC column for the $65 Y Z$ sample. (B) corresponding indexed selectedarea electron diffraction pattern. The transmitted beam zone is marked *, and the zone axis is marked as $B$. 


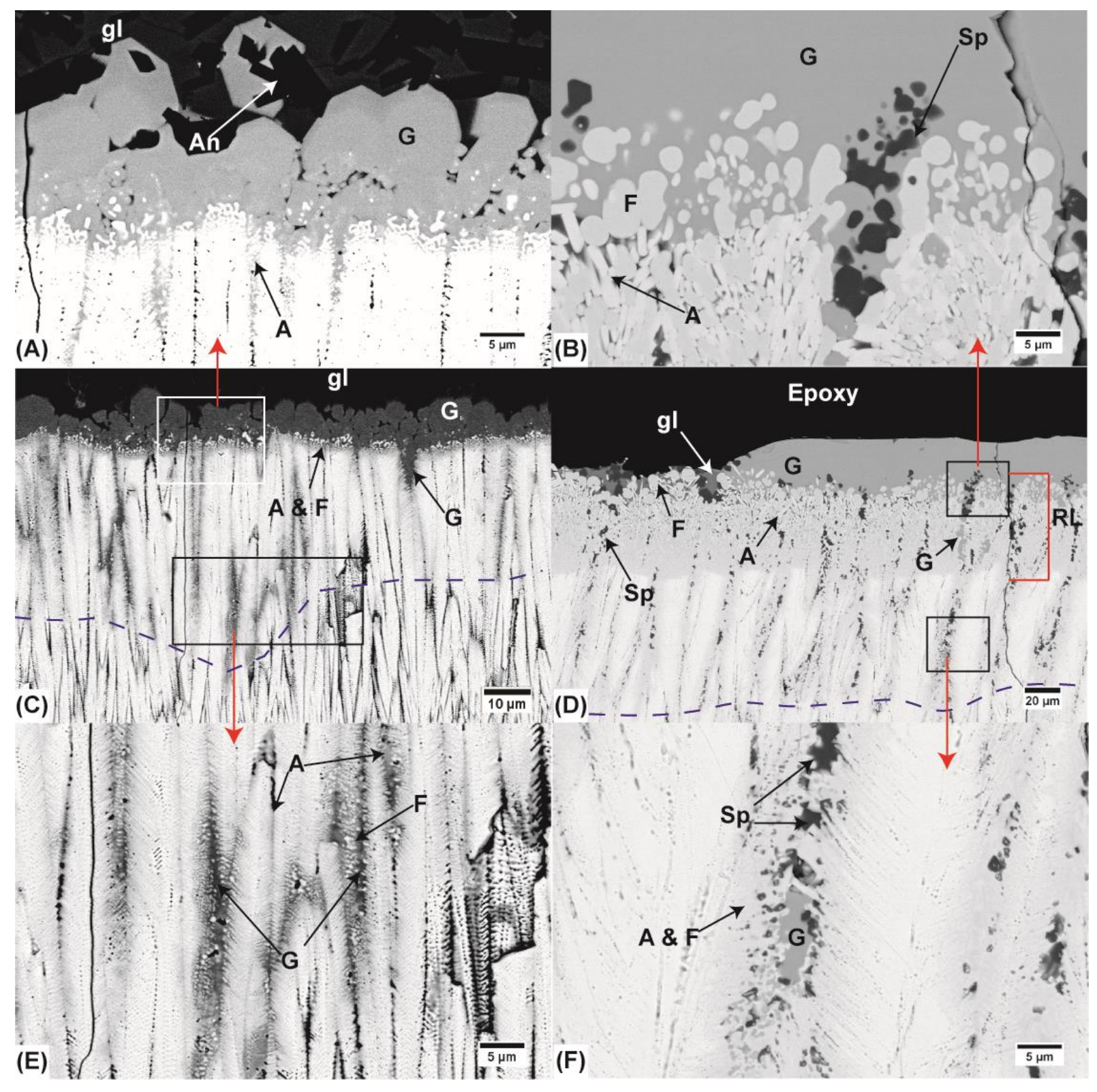

Figure 3: SEM cross-section image for the $C_{22} M_{11} A_{20} S_{38} F_{8} T_{1}$ reacted samples after 50 hrs at $1250^{\circ} \mathrm{C}$. (A) shows the top reaction zone for $65 Y Z$ and (B) for GZO. (C) shows the infiltration image for $65 Y Z$ and (D) for GZO. The overall infiltration zone is delimited with the dashed lines in $C$ and $D$. The area labeled as $R L$ for $G Z O$ in $D$ represents the reaction layer, which combines the garnet and apatite/fluorite layer. (E) higher magnification image of the reaction in the infiltrated intercolumnar gaps for $65 Y Z$ and (F) GZO. 


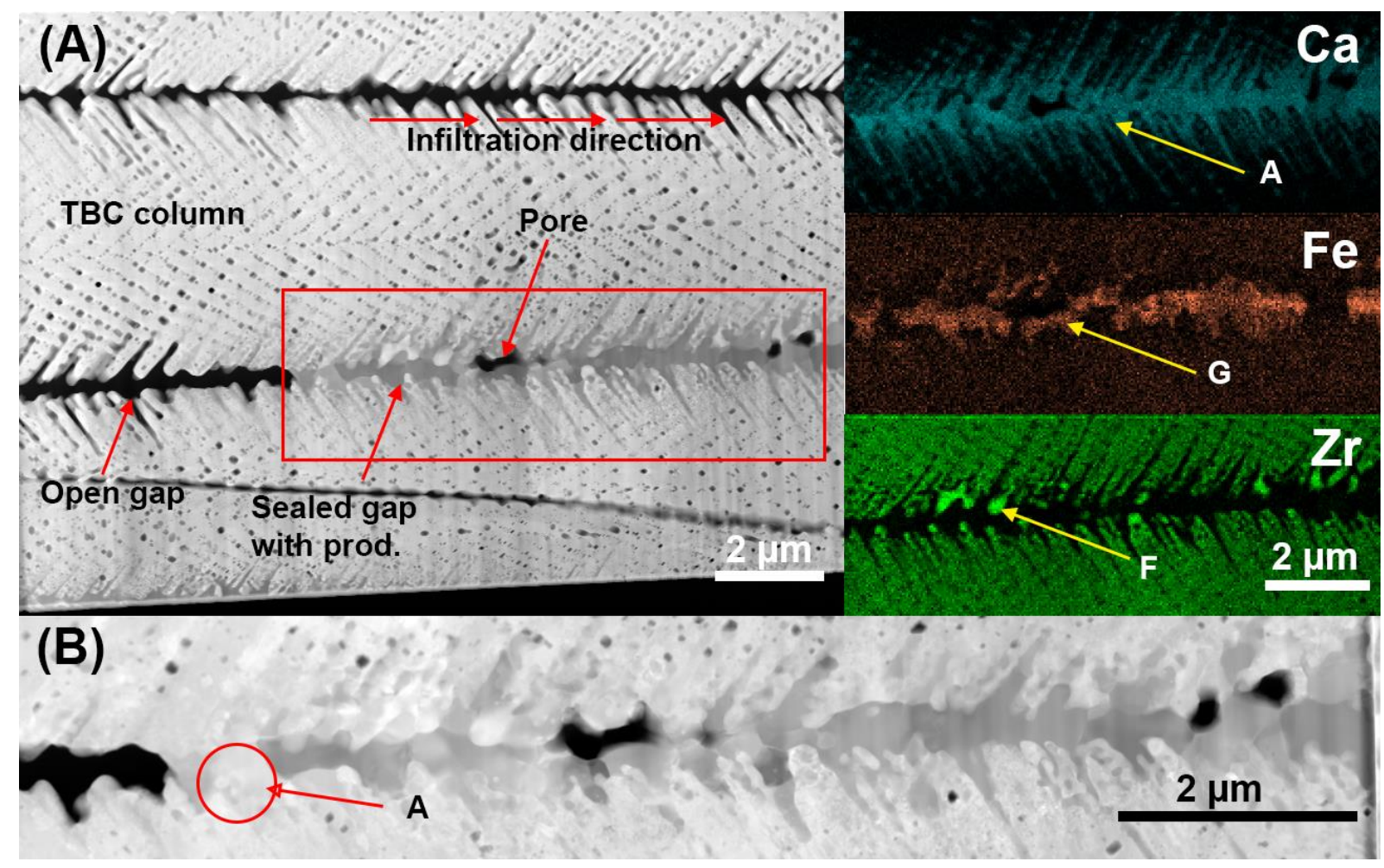

Figure 4: Cross-sectional TEM image of $(A)$ the analyzed area obtained from the bottom part of the infiltrated intercolumnar gap in a $65 Y Z$ coating after 5 hrs at y $1250{ }^{\circ} \mathrm{C}$ infiltration by $C_{22} M_{11} A_{20} S_{38} F_{8} T_{1}$ and (B) higher magnification image from the dotted rectangle with included elemental mappings. The small crystal marked as $A$ represents an apatite phase formed.

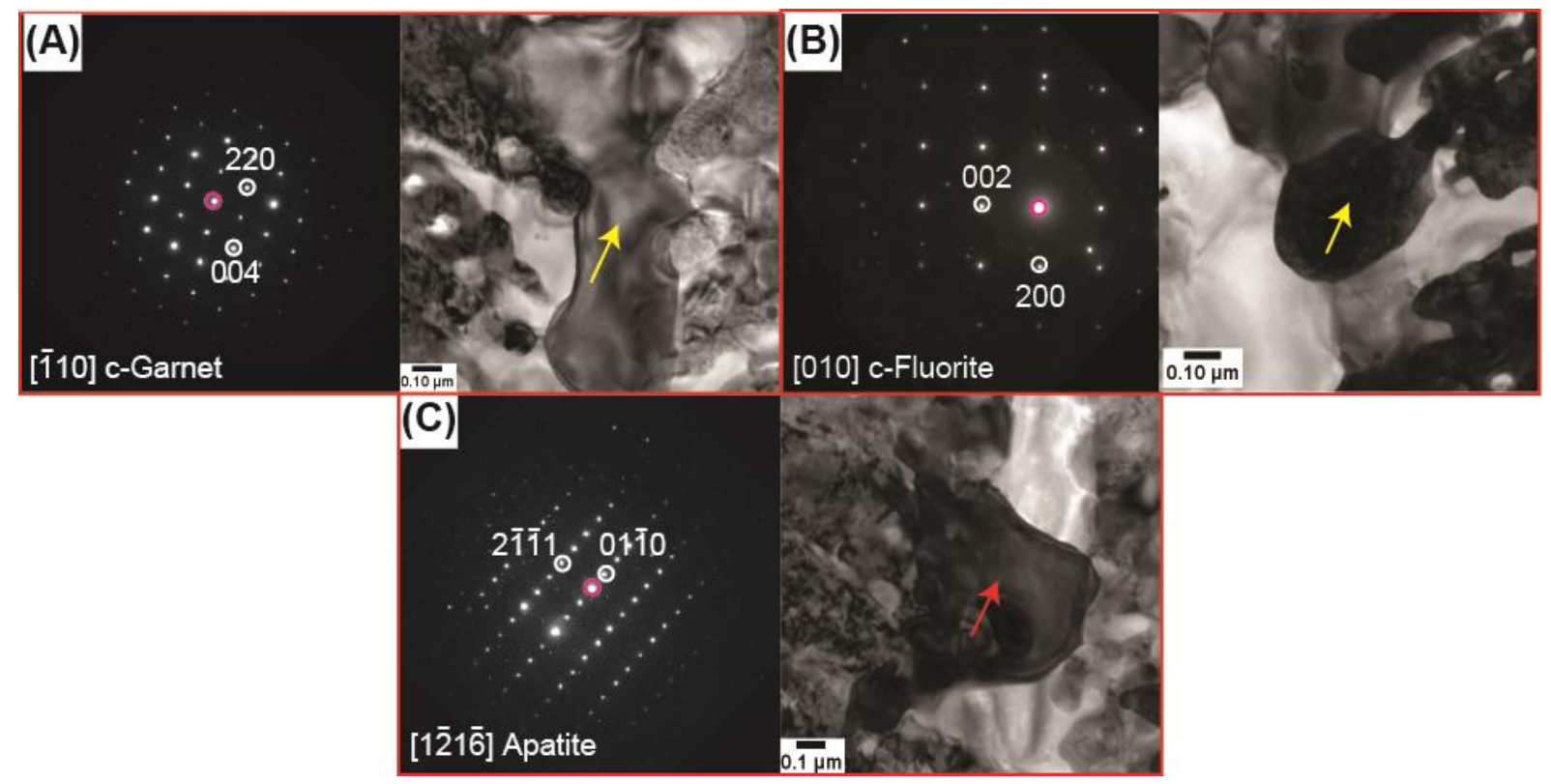

Figure 5: SAED pattern analysed in TEM obtained from Figure 4 ( $65 Y Z$ after $x 5 \mathrm{hrs}$ at $1250{ }^{\circ} \mathrm{C}$ infiltrated by $\left.C_{22} M_{11} A_{20} S_{38} F_{8} T_{1}\right)$ sample in Figure 4 identifying (A) the cubic garnet structure with its respective bright-field TEM image. (B) SAED pattern 
identifying the cubic fluorite structure with its respective bright-field TEM image. (C) SAED pattern identifying the hexagonal apatite structure with its respective bright-field TEM image.
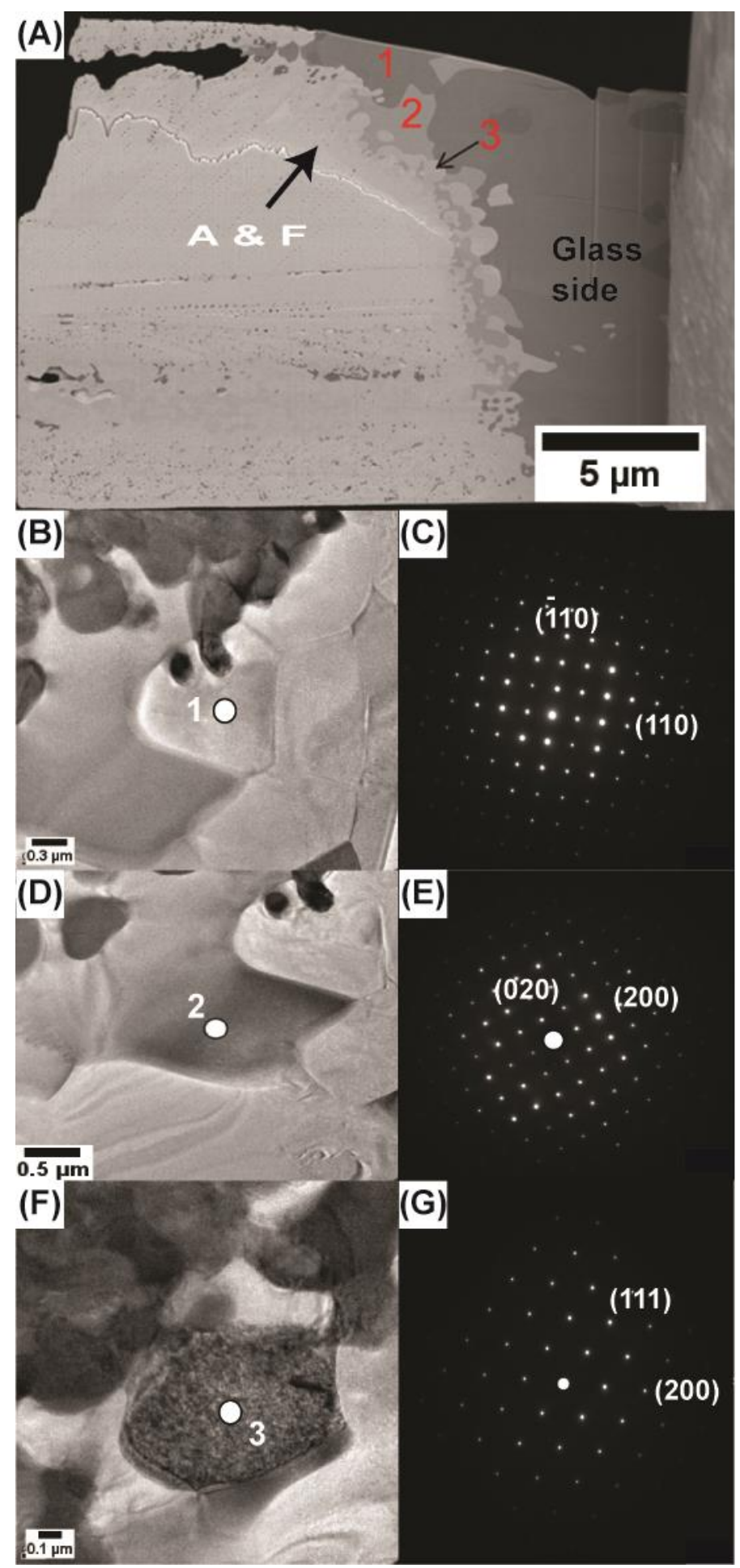

Figure 6:

TEM image (A) of the, analysed area obtained from the top reaction zone of GZO after $10 \mathrm{~h}$ at 1250 infiltrated by $C_{22} M_{11} A_{20} S_{38} F_{8} T_{1}$. (B) Bright-field TEM image of the indexed diopside particle labelled as number 1 in (A). (C) SAED pattern identifying the monoclinic diopside structure. (D) Bright-field TEM image of the indexed garnet particle labelled as number 2. (E) SAED pattern identifying the cubic garnet structure. (F) Bright-field TEM image of the indexed fluorite particle labelled as number 3. (E) SAED pattern identifying the cubic fluorite structure. 


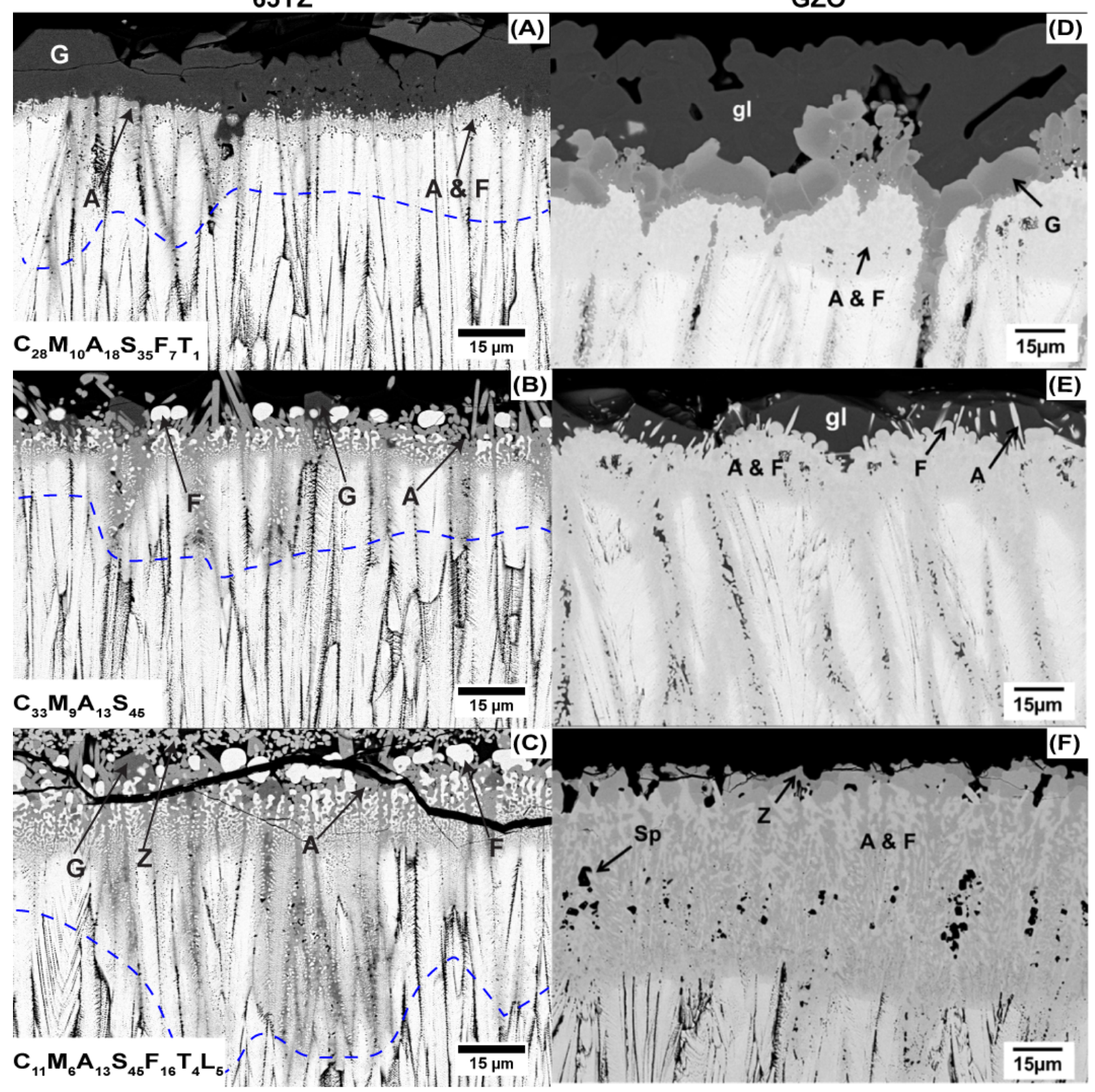

Figure 7: High magnification cross-section SEM image of the complementary tested CMAS/VA samples for $50 \mathrm{~h}$ at $1250{ }^{\circ} \mathrm{C}$. The dotted line indicates the discontinuous infiltration in the inter-columnar gaps. 


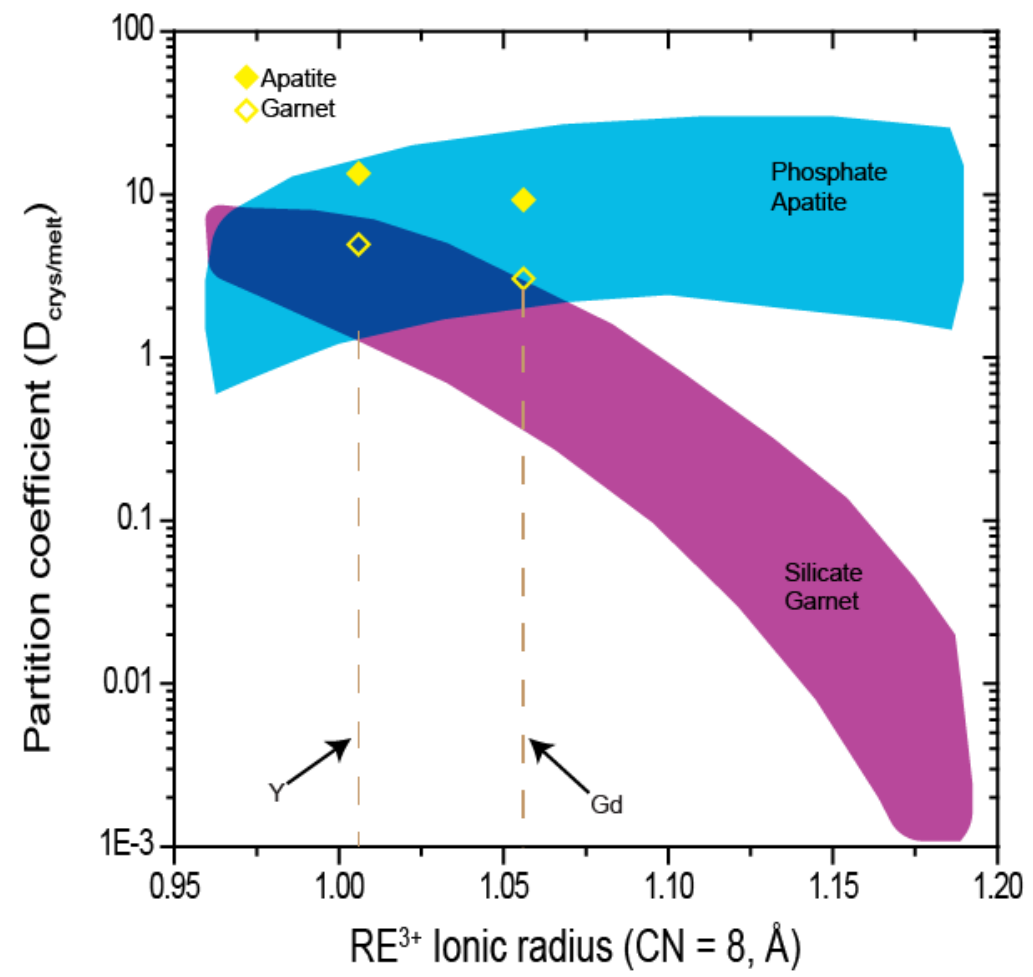

Figure 8: Partition coefficient plot vs. RE ionic radius incorporated from [29] with respect to other apatite and garnets with CMAS1??.

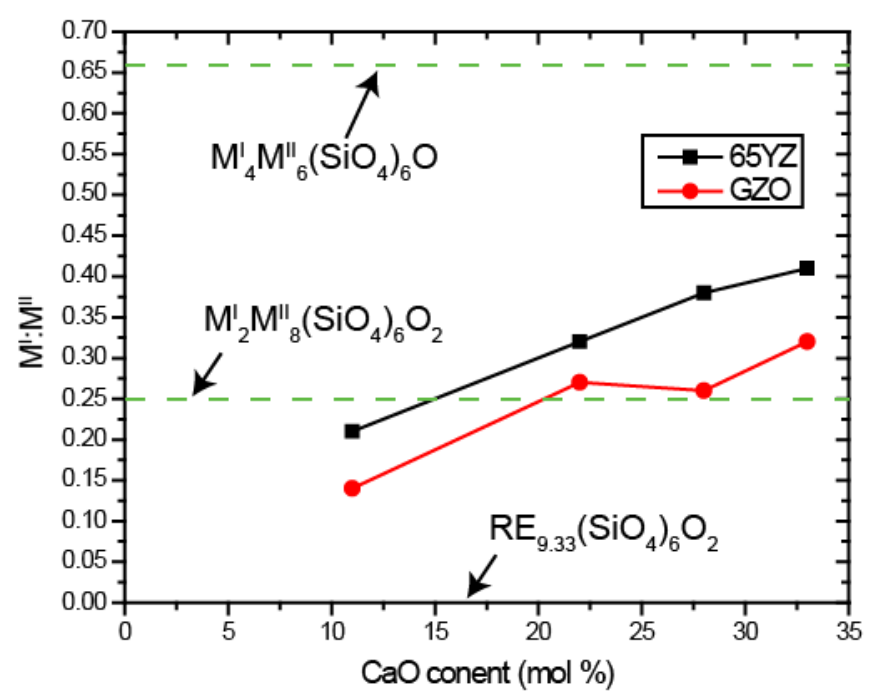

Figure 9: $\mathrm{M}^{\prime}: \mathrm{M}^{\prime \prime}$ ratio plot vs. the initial $\mathrm{CaO}$ concentration of the used CMAS sources listed in table 3 at $1250^{\circ} \mathrm{C}$ for $50 \mathrm{~h}$. The ratio is taken from the apatite composition at the reaction layer for $65 \mathrm{YZ}$ and GZO. 
Table 1: Summary of deposition parameters and microstructural features for the as coated $65 \mathrm{YZ}$ and GZO samples.

\begin{tabular}{|c|c|c|c|c|l|l|c|}
\hline $\begin{array}{c}\text { Sample } \\
\text { ID }\end{array}$ & $\begin{array}{c}\text { Thickness } \\
(\mu \mathrm{m})\end{array}$ & RPM & $\begin{array}{c}\text { Substrate } \\
\text { Temp. } \\
\left({ }^{\circ} \mathrm{C}\right)\end{array}$ & $\begin{array}{c}\text { Chamber Press. } \\
(\mathrm{mbar})\end{array}$ & $\begin{array}{l}\text { Porosity } \\
(\%)\end{array}$ & $\begin{array}{c}\text { Inter- } \\
\text { Average } \\
\text { column } \\
\text { diameter } \\
(\mu \mathrm{m})\end{array}$ & $\begin{array}{c}\text { Columnar } \\
\text { gap } \\
\text { width } \\
(\mu \mathrm{m})\end{array}$ \\
\hline $65 \mathrm{YZ}$ & $92-100$ & 12 & 950 & $6 \times 10^{-3}$ & $\begin{array}{l}29.7 \\
\pm 2.5\end{array}$ & $6.1 \pm 1.8$ & $0.8 \pm 0.4$ \\
\hline GZO & $330-340$ & 12 & 1000 & $6 \times 10^{-3}$ & 23.2 & \\
\pm 1.4 & $15.6 \pm 1.0$ & $1.7 \pm 1.3$ \\
\hline
\end{tabular}

Table 2: Summary of composition for the reaction products at the reaction layer for the $C_{22} M_{11} A_{20} S_{38} F_{8} T_{1}$ infiltrated samples for $50 \mathrm{~h}$ at $1250^{\circ} \mathrm{C}$.

\begin{tabular}{|c|c|c|c|c|c|c|c|c|}
\hline Sample & Label & Phase & Theoretical formula & $\mathrm{MgO}$ & $\mathrm{AlO}_{1.5}$ & $\mathrm{SiO}_{2}$ & $\mathrm{CaO}$ & $\mathrm{TiO}_{2}$ \\
\hline $65 \mathrm{YZ}$ & $\mathrm{An}$ & Anorthite & $\mathrm{CaAl}_{2} \mathrm{Si}_{2} \mathrm{O}_{8}$ & 0.5 & 35.1 & 40.3 & 22.1 & - \\
\hline & $\mathrm{G}$ & Garnet & $(\mathrm{RE}, \mathrm{Zr}, \mathrm{Ca})_{3}(\mathrm{Mg}, \mathrm{Al}, \mathrm{Fe}, \mathrm{Ti}, \mathrm{Zr})_{2}(\mathrm{Si}, \mathrm{Al}, \mathrm{Fe})_{3} \mathrm{O}_{12}$ & 7.7 & 11.7 & 23.8 & 19.6 & 1.7 \\
\hline & $\mathrm{A}$ & Apatite & $(\mathrm{RE}, \mathrm{Ca})_{4}(\mathrm{RE}, \mathrm{Zr})_{6}\left(\mathrm{SiO}_{4}\right)_{6} \mathrm{O}_{2}$ & 1.4 & 1.9 & 30.1 & 15.0 & - \\
\hline & $\mathrm{F}$ & Fluorite & $(\mathrm{RE}, \mathrm{Zr}, \mathrm{Ca}) \mathrm{O}_{1 . x}$ & 2.9 & 4.3 & 6.6 & 7.5 & 1.4 \\
\hline & $\mathrm{gl}$ & Glass & - & 10.8 & 12.6 & 36.8 & 24.4 & 1.8 \\
\hline $\mathrm{GZO}$ & $\mathrm{Sp}$ & Spinel & $\left(\mathrm{MgAl}{ }_{2-x} \mathrm{Fe}_{x}\right) \mathrm{O}_{4}$ & 27.6 & 57.8 & - & 0.3 & - \\
\hline & $\mathrm{G}$ & Garnet & $(\mathrm{RE}, \mathrm{Zr}, \mathrm{Ca})_{3}(\mathrm{Mg}, \mathrm{Al}, \mathrm{Fe}, \mathrm{Ti}, \mathrm{Zr})_{2}(\mathrm{Si}, \mathrm{Al}, \mathrm{Fe})_{3} \mathrm{O}_{12}$ & 4.5 & 9.7 & 18.8 & 21.6 & 2.1 \\
\hline & $\mathrm{A}$ & Apatite & $\left.(\mathrm{RE}, \mathrm{Ca})_{4}(\mathrm{RE}, \mathrm{Zr})_{6}(\mathrm{SiO})_{4}\right)_{6} \mathrm{O}_{2}$ & - & - & 31.9 & 14.5 & - \\
\hline & $\mathrm{F}$ & Fluorite & $(\mathrm{RE}, \mathrm{Zr}, \mathrm{Ca}) \mathrm{O}_{1 . x}$ & - & - & - & 3.3 & 1.9 \\
\hline & $\mathrm{gl}$ & Glass & - & 6.9 & 15.8 & 33.9 & 29.7 & 1.3 \\
\hline
\end{tabular}

Table 3: Summary of composition for the reaction products at the reaction layer for the complementary infiltrated $65 \mathrm{YZ}$ and GZO samples for $50 \mathrm{~h}$ at $1250^{\circ} \mathrm{C}$.

\begin{tabular}{|c|c|c|c|c|c|c|c|c|c|}
\hline CMAS compound & Sample & ID & $\mathrm{MgO}$ & $\mathrm{AlO}_{1.5}$ & $\mathrm{SiO}_{2}$ & $\mathrm{CaO}$ & $\mathrm{TiO}_{2}$ & $\mathrm{FeO}$ & $\mathrm{REO}_{1.5}$ \\
\hline \multirow[t]{7}{*}{$\mathrm{C}_{28} \mathrm{M}_{10} \mathrm{~A}_{18} \mathrm{~S}_{35} \mathrm{~F}_{7} \mathrm{~T}_{1}$} & $65 Y Z$ & $A$ & 1.7 & 1.8 & 29.5 & 16.5 & & 2.1 & 40.3 \\
\hline & $65 Y Z$ & $\mathrm{G}$ & 8.5 & 5.4 & 27.8 & 25.2 & 1.8 & 14.2 & 13.4 \\
\hline & $65 Y Z$ & $\mathrm{~F}$ & 3.1 & 2.3 & 13.2 & 12.7 & 1.4 & 2.4 & 24.4 \\
\hline & $65 Y Z$ & $\mathrm{gl}$ & 8.9 & 9.4 & 39.8 & 30.9 & 0.9 & 4.6 & 3.3 \\
\hline & GZO & $A$ & 0 & 0 & 30.3 & 14.4 & 0 & 0 & 49.7 \\
\hline & GZO & G & 5.5 & 6.2 & 21.6 & 27.9 & 1.8 & 15 & 12.2 \\
\hline & GZO & $\mathrm{gl}$ & 17.6 & 3.8 & 38.3 & 40.3 & - & - & - \\
\hline \multirow[t]{5}{*}{$\mathrm{C}_{33} \mathrm{M}_{9} \mathrm{~A}_{13} \mathrm{~S}_{45}$} & $65 Y Z$ & $A$ & 0.4 & 0.7 & 33.8 & 18.8 & & & 40.9 \\
\hline & $65 Y Z$ & G & 11.4 & 16.5 & 31.2 & 22.5 & - & - & 18.4 \\
\hline & $65 Y Z$ & $\mathrm{~F}$ & - & - & - & 3.9 & - & - & 25.7 \\
\hline & $65 Y Z$ & $\mathrm{gl}$ & 7.5 & 13.6 & 36.7 & 34 & - & - & 6.1 \\
\hline & GZO & $A$ & - & - & 31.2 & 16.8 & - & - & 47.3 \\
\hline
\end{tabular}




\begin{tabular}{|c|c|c|c|c|c|c|c|c|c|}
\hline & GZO & $\mathrm{F}$ & - & - & - & 6.8 & - & - & 19 \\
\hline & GZO & gl & 11.3 & 17 & 32 & 39.8 & - & - & - \\
\hline \multirow[t]{10}{*}{$\mathrm{C}_{11} \mathrm{M}_{6} \mathrm{~A}_{13} \mathrm{~S}_{45} \mathrm{~F}_{16} \mathrm{~T}_{4} \mathrm{~L}_{5}$} & $65 Y Z$ & A & 1 & - & 32.8 & 10.7 & 0.3 & 0.3 & 49.1 \\
\hline & $65 Y Z$ & G & 8.7 & 11.7 & 17.8 & 7.7 & 0.9 & 23.5 & 27.0 \\
\hline & $65 Y Z$ & $\mathrm{~F}$ & 0.0 & 0.0 & 0.0 & 0.0 & 3.6 & 4.7 & 24.5 \\
\hline & $65 Y Z$ & Z & 0.4 & 4.3 & 3.5 & 1.5 & 20.5 & 18.3 & 23.5 \\
\hline & $65 Y Z$ & gl & 5.1 & 16.2 & 43.1 & 9.1 & 2.1 & 10.9 & 12.1 \\
\hline & GZO & A & - & - & 30 & 8.7 & - & - & 54.3 \\
\hline & GZO & $\mathrm{F}$ & - & - & - & - & 3.6 & 4.7 & 24.5 \\
\hline & $\mathrm{GZO}$ & $\mathrm{Sp}$ & 21.6 & 54.6 & - & - & - & 19.6 & 1.1 \\
\hline & GZO & Z & -- & 3.6 & - & 1.8 & 21 & 18.1 & 25 \\
\hline & GZO & gl & - & - & - & - & - & - & \\
\hline
\end{tabular}

Table 4: Summary of the composition of the tested CMAS sources specified in Figure 8. $M^{\prime}$ to $M^{\prime \prime}$ denotes the cation site content of the apatite phase (Ca, Mg for $\mathrm{M}^{\prime}$ and $\mathrm{RE}, \mathrm{Zr}$ for $\left.\mathrm{M}^{\prime \prime}\right)$.

$M^{\prime}: M^{\prime \prime}$

\begin{tabular}{|c|c|c|c|c|}
\hline Melt composition & $\begin{array}{l}\mathrm{CaO} \\
(\mathrm{mol} \%)\end{array}$ & ID & $65 Y Z$ & GZO \\
\hline $\mathrm{C}_{22} \mathrm{M}_{11} \mathrm{~A}_{20} \mathrm{~S}_{38} \mathrm{~F}_{8} \mathrm{~T}_{1}$ & 22 & CMAS 1 & 0.32 & 0.27 \\
\hline $\mathrm{C}_{28} \mathrm{M}_{10} \mathrm{~A}_{18} \mathrm{~S}_{35} \mathrm{~F}_{7} \mathrm{~T}_{1}$ & 28 & CMAS 2 & 0.38 & 0.26 \\
\hline $\mathrm{C}_{11} \mathrm{M}_{6} \mathrm{~A}_{13} \mathrm{~S}_{45} \mathrm{~F}_{16} \mathrm{~T}_{4} \mathrm{~L}_{5}{ }^{\mathrm{a}}$ & 11 & $\begin{array}{l}\text { Iceland } \\
\text { Volcanic } \\
\text { ash }\end{array}$ & 0.21 & 0.14 \\
\hline $\mathrm{C}_{33} \mathrm{M}_{9} \mathrm{~A}_{13} \mathrm{~S}_{45}$ & 33 & $\begin{array}{l}\text { UCSB } \\
\text { CMAS }\end{array}$ & 0.41 & 0.32 \\
\hline
\end{tabular}

a $\mathrm{L}$ represents the sum of $\mathrm{NaO}_{0.5}$ and $\mathrm{KO}_{0.5}$ 